\title{
Rapamycin-topotecan combination exhibited enhanced antitumor efficacy compared to topotecan used alone in cisplatin-resistant ovarian cancer cells
}

\author{
G. SUN ${ }^{1}$, Z. GUO ${ }^{2}, \mathrm{X} \cdot \mathrm{LI}^{3, *}$ \\ ${ }^{1}$ Department of Oncology, Liaocheng People's Hospital, Liaocheng, Shandong, China; ${ }^{2}$ Department of Obstetrics and Gynecology, Liaocheng \\ People's Hospital, Liaocheng, Shandong, China; ${ }^{3}$ Out-Patient Infusion Center, Liaocheng People's Hospital, Liaocheng, Shandong, China
}

${ }^{*}$ Correspondence: lixh-lc@outlook.com

Received January 7, 2015 / Accepted May 11, 2015

\begin{abstract}
The present study aimed to investigate the antitumor efficacy of combination of topotecan with rapamycin, a mTOR inhibitor, in cisplatin-resistant ovarian cancer cells A2780cis and COC1/DDP.

Expressions of mTOR and its target molecules $\mathrm{p} 70 \mathrm{~S} 6 \mathrm{~K}$ and 4E-BP1 were determined in A2780cis and COC1/DDP and the parental cells A2780 and COC1 that are sensitive to cisplatin using Western blotting. Cell proliferation was examined using MTT assay in vitro and a nude mouse model in vivo, respectively. Cell apoptosis and the relevant proteins were determined by flow cytometry and Western blotting.

We found that the levels of phosphorylated mTOR, p70S6K, and 4E-BP1 were obviously higher in A2780cis and COC1/ DDP cells than that in A2780 and COC1 cells. Pretreatment with rapamycin significantly enhanced the effects of topotecan in suppressing cell proliferation and soliciting cell apoptosis in A2780cis and COC1/DDP cells. Cells that were sequentially exposed to rapamycin and topotecan had significantly higher levels of cleaved caspase- $8,-3$, and PARP compared to those treated with topotecan alone. Mice co-administered rapamycin and topotecan had significantly decreased terminal tumor burden without additional loss of bodyweight compared to the mice received topotecan alone.

The results suggested that rapamycin sensitized A2780cis and COC1/DDP cells to topotecan-induced apoptosis and rapamycin-topotecan combination might have a value in treatment of cisplatin-resistant ovarian cancer.
\end{abstract}

Key words: topotecan, rapamycin, mTOR, A2780cis, COC1/DDP

Ovarian cancer is the most malignant type of gynecological cancers with poor prognosis. It was estimated that there were 239,000 new cases and 152,000 deaths in the world in 2012 according to the statistics published by World Health Organization (WHO) [1]. Most patients are diagnosed at advanced stages because the disease is usually occult in onset and has no obvious symptoms at early stage. For these patients, combination of surgical reduction with cisplatin-based chemotherapy is a standard and first-line therapeutic regimen and obviously prolongs the patients' life. However, ovarian cancer has been challenging to treat because it tends to develop resistance to platinum drugs during the primary chemotherapy. In addition, less than $15 \%$ of patients who are diagnosed with advanced ovarian cancer achieve long-term remission after first-line therapy [2]. At first relapse, approximately $25 \%$ of patients have platinum-resistant tumors and almost all patients with recurrent disease ultimately develop platinum resistance [3].
Thus, an efficient second-line treatment regimen is critical to increase the survival time of patients with platinum-resistant ovarian cancer.

Topotecan, a topoisomerase I (Topo I) inhibitor, is recently used to treat ovarian cancer. Studies demonstrated that it is also effective for recurrent or platinum-resistant ovarian cancer [4]. However, topotecan could be benefit only in a small fraction of such patients with overall response rates $20-30 \%$ and the median survival time was found to be only 59.7 weeks [5-7]. Enhancement of the efficacy of topotecan by using in combination regimen is a rational strategy. Rapamycin is a mTOR inhibitor that shows potent antitumor activity in a variety of malignances including ovarian cancers in preclinical and clinical studies [8-10]. Notably, rapamycin and its derivatives have been demonstrated to enhance the efficacy of cytotoxic chemotherapeutic drugs including topotecan, oxaliplatin, and 5-fluorouracil (5-FU) against various types of cancers such 
as endometrial, gastric and colon cancer [8, 11-14]. Given that mTOR signaling pathway was shown to be hyperactivated in platinum-resistant ovarian carcinoma cells [15], we investigated the efficacy of combination of topotecan with rapamycin against cisplatin-resistant ovarian carcinoma in the present study.

\section{Materials and methods}

Agents. Rapamycin and topotecan were purchased from Sigma-Aldrich (St. Louis, MO, USA). Rapamycin oral solution (Rapamune ${ }^{\odot}$ ) and topotecan for injection $\left(\right.$ Hycamtin $\left.^{\circ}\right)$ were obtained from Wyeth Pharmaceuticals Inc. (Rouses Point, NY, USA) and GlaxoSmithKline Manufacturing S.p.A (Brentford, London, UK), respectively. For in vitro assay, rapamycin was firstly dissolved in dimethyl sulfoxide (DMSO; Sigma-Aldrich) and further diluted in phosphate buffer solution (PBS) before use; topotecan was dissolved in PBS before use. For in vivo study, rapamycin oral solution and topotecan for injection were given by gavage and intravenous injection, respectively.

Cell line and cell culture. Human epithelial ovarian cancer cells A2780 (cisplatin-sensitive) and A2780cis (cisplatinresistant) cells were obtained from European Collection of Cell Cultures (ECACC). Human ovarian mucinous adenocarcinoma cells COC1 (cisplatin-sensitive) and COC1/DDP (cisplatin-resistant) were purchased from China Center for Type Culture Collection (CCTCC; Wuhan, China). Cells were cultured according to the ECACC and CCTCC instructions. Briefly, cells were cultured in RPMI 1640 supplemented with $10 \%$ fetal bovine serum (FBS) at $37^{\circ} \mathrm{C}$ in a humid atmosphere ( $5 \% \mathrm{CO}_{2}-95 \%$ air). Cells were harvested by brief incubation in $0.02 \%(\mathrm{w} / \mathrm{v})$ ethylenediaminetetraacetic acid (EDTA) in PBS.

Cell proliferation assay. Cells $\left(1 \times 10^{4}\right.$ per well $)$ seeded in 96-well plates were exposed to rapamycin, topotecan, or their combination for specified time. For combination therapy, cells were treated with $10 \mathrm{nM}$ rapamycin and then incubated with increasing concentrations of topotecan. Rapamycin was removed from the cultures prior to the addition of topotecan, hence the drugs were not present in the culture at the same time. The 3-(4,5-dimethylthiazol-2-yl)-2,5-diphenyltetrazolium bromide (MTT) assay was performed by adding $20 \mu \mathrm{L}$ of MTT ( $5 \mathrm{mg} / \mathrm{mL}$, Sigma-Aldrich) for $4 \mathrm{~h}$. Light absorbance of the solution was measured at $570 \mathrm{~nm}$ on a microplate reader (Perkin-Elmer, USA).

Annexin V/FITC/PI staining assay. The apoptotic cells were estimated by determining the levels of phosphatidylserine on cell surface. Cells seeded in $25-\mathrm{cm}^{2}$ culture flasks $(1.5 \times$ $10^{5}$ cells per $\mathrm{mL} ; 6 \mathrm{~mL}$ per flask) were exposed to rapamycin, topotecan, or their combination. For combination therapy, cells were treated with $10 \mathrm{nM}$ rapamycin and then incubated with increasing concentrations of topotecan. Rapamycin was removed from the cultures prior to the addition of topotecan. The levels of phosphatidylserine were determined by using
Annexin-V/FITC and PI kit (Labtek, Dalian, Liaoning, China). The experiment was performed on a FACScan flow cytometry. The population of apoptotic cells was estimated by comparing to the vehicle control.

Western blot analysis. Cells $\left(3.0 \times 10^{5}\right.$ per well $)$ seeded in 6-well plates were exposed to rapamycin, topotecan, or their combination for specified time period. For combination therapy, cells were treated with $10 \mathrm{nM}$ rapamycin and then incubated with $100 \mathrm{nM}$ topotecan. Rapamycin was removed from the cultures prior to the addition of topotecan. Cells were harvested and cell lysates ( $30 \mu \mathrm{g}$ of protein per lane) were fractionated by $10 \%$ SDS-PAGE. The proteins were electrotransferred onto nitrocellulose membrane and the protein levels were detected using the primary antibodies against p53 and phosphorylated mTOR, p70S6K, 4E-BP1, caspase-3 and -8 , cleaved PARP, and $\beta$-actin (Santa Cruz, Dallas, TX, USA) with appropriate dilution. The bound antibodies were visualized using an enhanced chemiluminescence reagent and quantified by densitometry using ChemiDoc XRS+ image analyzer (Bio-Rad, Hercules, CA, USA). Densitometric analyses of bands were adjusted with $\beta$-actin as loading control. The percentages of increase or decrease of protein were estimated by comparison to the vehicle control (100\%).

In vivo inhibition of tumor growth. The in vivo efficacy of combination of rapamycin and topotecan was assessed in an A2780cis xenograft mouse model. Balb/c athymic (nu+/ $\mathrm{nu}+$ ) female mice, 4-6 weeks of age, were purchased from the Animal Center of China Academy of Medical Sciences (Beijing, China). The animals were housed under pathogenfree conditions. The research protocol was in accordance with the institutional ethic guideline of the Animal Care and Use Committee at Liaocheng People's Hospital.

Tumors were generated by harvesting A2780cis cells from mid-log phase cultures. Cells were then pelleted and resuspended in PBS to a final cell count of $5 \times 10^{7} / \mathrm{mL}$. A volume of $0.2 \mathrm{~mL}$ of the cell suspension was injected s.c. in the right flank of each mouse. After 7 days, when the tumor volume had reached approximately $0.1 \mathrm{~cm}^{3}$, the mice were divided into 4 groups $(n=6)$ and then subjected to treatment. Group 1: mice were injected with $0.2 \mathrm{~mL}$ normal saline via tail vein. Group 2: rapamycin was administered p.o. at $1.5 \mathrm{mg} / \mathrm{kg}$. Group 3: topotecan was administered i.v. at $1.0 \mathrm{mg} / \mathrm{kg}$. Group 4: mice received $1.5 \mathrm{mg} / \mathrm{kg}$ of rapamycin (p.o.) at 7:00 AM and $1.0 \mathrm{mg} /$ $\mathrm{kg}$ of topotecan (i.v.) at 7:00 PM. Administration of vehicle, rapamycin, topotecan, or their combination was performed daily for 14 days. Tumors were harvested at the end of experiment and tumor growth rates were defined as a percentage of the control tumor weight.

Statistical analysis. Data were expressed as mean \pm S.D. for three different determinations. Statistical significance was analyzed by one-way analysis of variance (ANOVA) followed by Dunnett's multiple range tests. $p<0.05$ was considered as statistically significant. Statistical analysis was performed using the SPSS/Win 12.0 software (SPSS, Inc, Chicago, IL, USA). 
Results

Hyperactivation of mTOR signal pathway in cisplatinresistant ovarian cancer cells. Given that mTOR signal transduction pathway has an essential role in the regulation of cell survival and suppression of this pathway may sensitize cancer cells to cytotoxic drugs [16], we first determined the levels of molecules implicated in mTOR pathway in cisplatinresistant ovarian cancer cells A2780cis and COC1/DDP using Western blotting. As shown in Figure 1, expression of phosphorylated mTOR (p-mTOR) is obviously increased by 33.6 and $37.5 \%$ in A2780cis and COC1/DDP, respectively, compared to their parental cell lines A2780 and COC1. p70S6K and 4E-BP1 are known to be the target molecules of mTOR. Our results demonstrated that the levels of phosphorylated p70S6K and 4E-BP1 (p-p70S6K and p-4E-BP1) were increased by 35.8 and $39.3 \%$ in A2780cis, and by 68.2 and $77.6 \%$ in COC1/DDP, compared to the parental non-resistant cells (Figure 1). These results suggested that mTOR signal transduction is hyperactive in cisplatin-resistant ovarian cancer cells A2780cis and COC1/DDP.

Pretreatment of rapamycin enhanced the anti-proliferation effect of topotecan. The efficacy of topotecan monotherapy was first tested in the cisplatin-resistant cells A2780cis and COC1/DDP. The two cell lines were cultured

\section{A2780 A2780cis COC1 COC1/DDP}
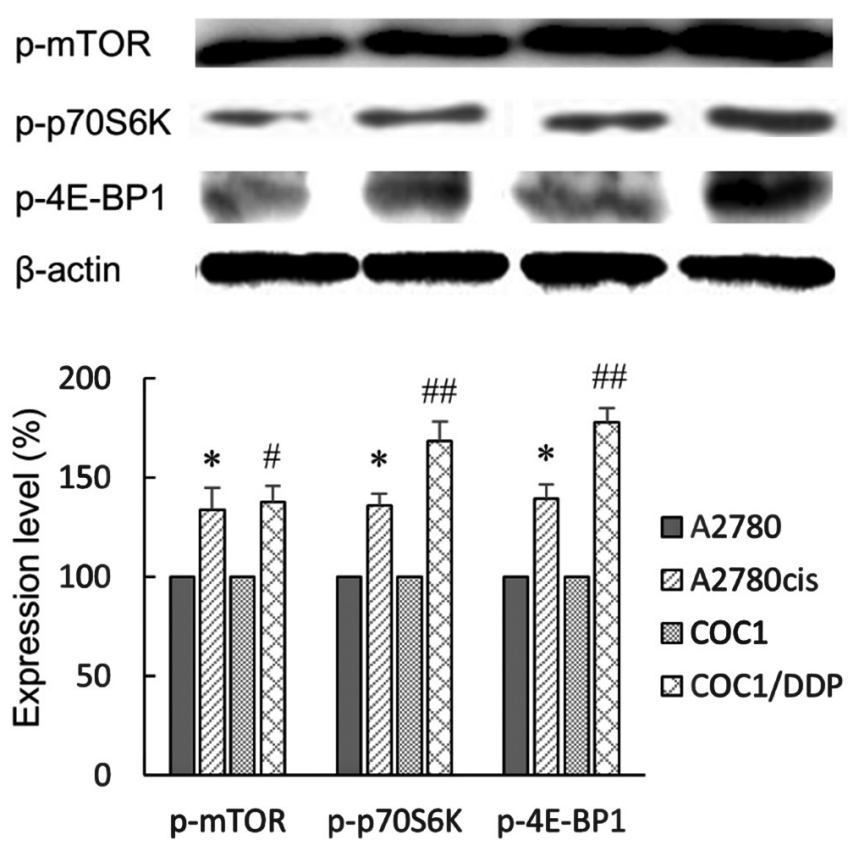

Figure 1. Expression levels of phosphorylated mTOR, p70S6K, and 4E-BP1 in cisplatin-resistant cells A2780cis and COC1/DDP and cisplatin-sensitive cells A2780 and COC1. Each kind of cells were cultured according to the instruction and lysed in RIPA buffer. Total proteins were subjected to Western blotting. ${ }^{*} p<0.05$, A2780cis vs. A2780. ${ }^{\#} p<0.05,{ }^{\# \#} p<0.01$, COC1/DDP vs. COC1. in medium for $24 \mathrm{~h}$ and then treated with increasing doses of the drug $(10,50,100,500$, and $1,000 \mathrm{nM})$ for $48 \mathrm{~h}$ and cell proliferation was determined using MTT assay. These concentrations of topotecan represent a range that typically bracket therapeutic dose levels achieved in the circulation [17]. Results showed that topotecan at designed concentrations inhibited cell proliferation by $5.8,11.6,22.5,33.8$, and $45.3 \%$, respectively, in A2780cis cells; by 7.1, 16.3, 25.9, 40.1, and 52.1\%, respectively, in COC1/DDP cells (Figure 2).

To determine whether rapamycin could sensitize cells to topotecan-induced growth inhibition, A2780cis and COC1/ DDP were pretreated with rapamycin $(10 \mathrm{nM})$ for $24 \mathrm{~h}$ followed by treatment with increasing doses of topotecan for $48 \mathrm{~h}$. The concentration of rapamycin used in the combination therapy was selected at $10 \mathrm{nM}$ based on that rapamycin at this
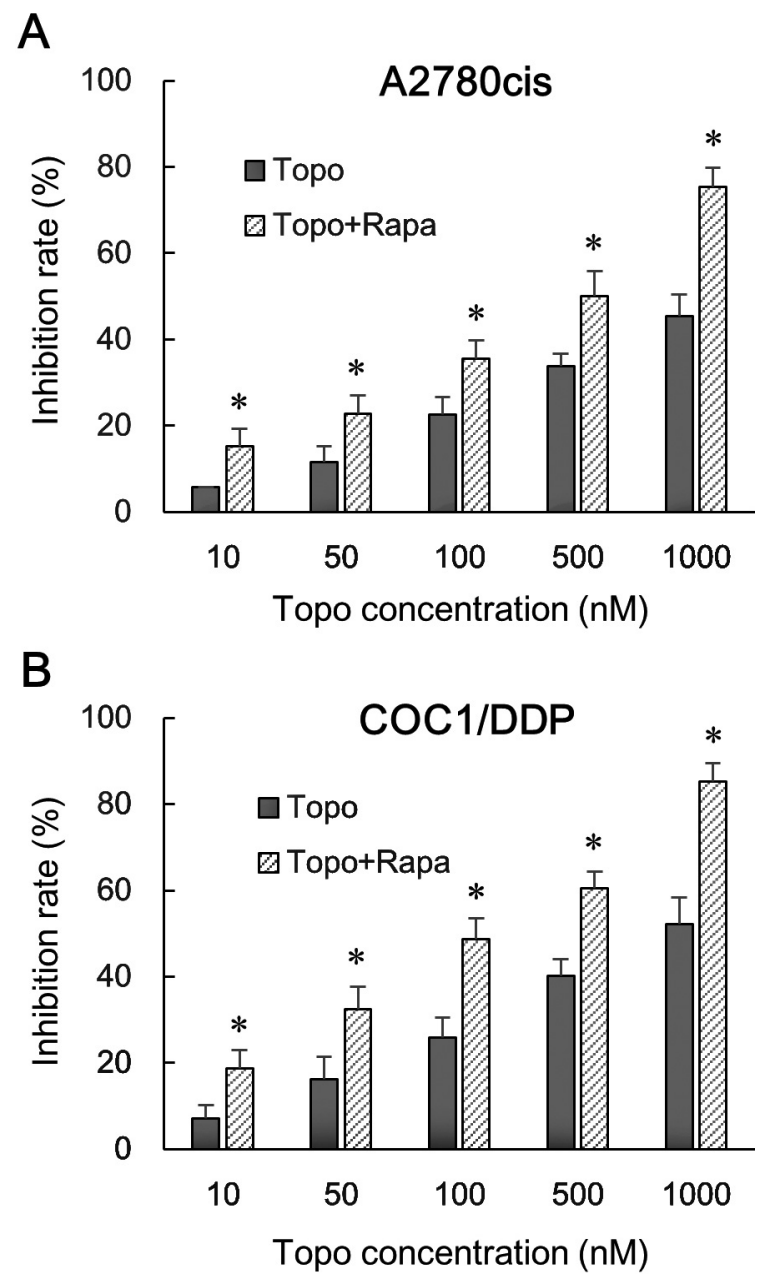

Figure 2. Effect of rapamycin pretreatment on topotecan-induced cell growth inhibition in A2780cis (A) and COC1/DDP (B) cells. Cells were exposed to the following treatments: i) vehicle for $24 \mathrm{~h}$ followed by topotecan at a concentration range of $10-1,000 \mathrm{nM}$ for $48 \mathrm{~h}$; ii) $10 \mathrm{nM}$ rapamycin for $24 \mathrm{~h}$ followed by increasing doses of topotecan (10-1,000 $\mathrm{nM}$ ) for $48 \mathrm{~h}$. Cells were then subjected to MTT assay. ${ }^{\star} p<0.05$, combined treatment $v s$. topotecan alone treatment. Topo, topotecan; Rapa, rapamycin. 
dose for $24 \mathrm{~h}$ exposure did not significantly affect the proliferation of A2780cis and COC1/DDP in a pilot experiment. Results showed that pretreatment of rapamycin enhanced the inhibitory effect of topotecan on the proliferation of two cell lines (Figure 2). Inhibitory rates of rapamycin-topotecan combination (topotecan at 10,50,100,500, and 1,000 nM) were determined to be $15.3,22.8,35.6,50.1$, and $75.3 \%$, respectively, in A2780cis cells, and 18.7, 32.5, 48.6, 60.5, and 85.3\%, respectively, in COC1/DDP cells. There is a significant difference in inhibition rate at each concentration between topotecan monotherapy and combined therapy $(p<0.05$; Figure 2$)$.
Pretreatment of rapamycin enhanced cell apoptosis induced by topotecan. We next determined topotecan-induced cell apoptosis with or without rapamycin pretreatment using flow cytometry. Topotecan alone at doses of 10, 100, and $1,000 \mathrm{nM}$ for $48 \mathrm{~h}$ exposure induced apoptotic rates of 7.5, 15.6, and 23.6\%, respectively, in A2780cis cells; 8.6, 17.5, and $26.9 \%$, respectively, in COC1/DDP cells. Rapamycin at $10 \mathrm{nM}$ for $24 \mathrm{~h}$ exposure had no apparent effect on cell apoptosis in A2780cis and COC1/DDP cells (Figure 3). When pretreatment with $10 \mathrm{nM}$ rapamycin for $24 \mathrm{~h}$ followed by treatment with 10,100 , and 1,000 nM topotecan for $48 \mathrm{~h}$, percentages of

A
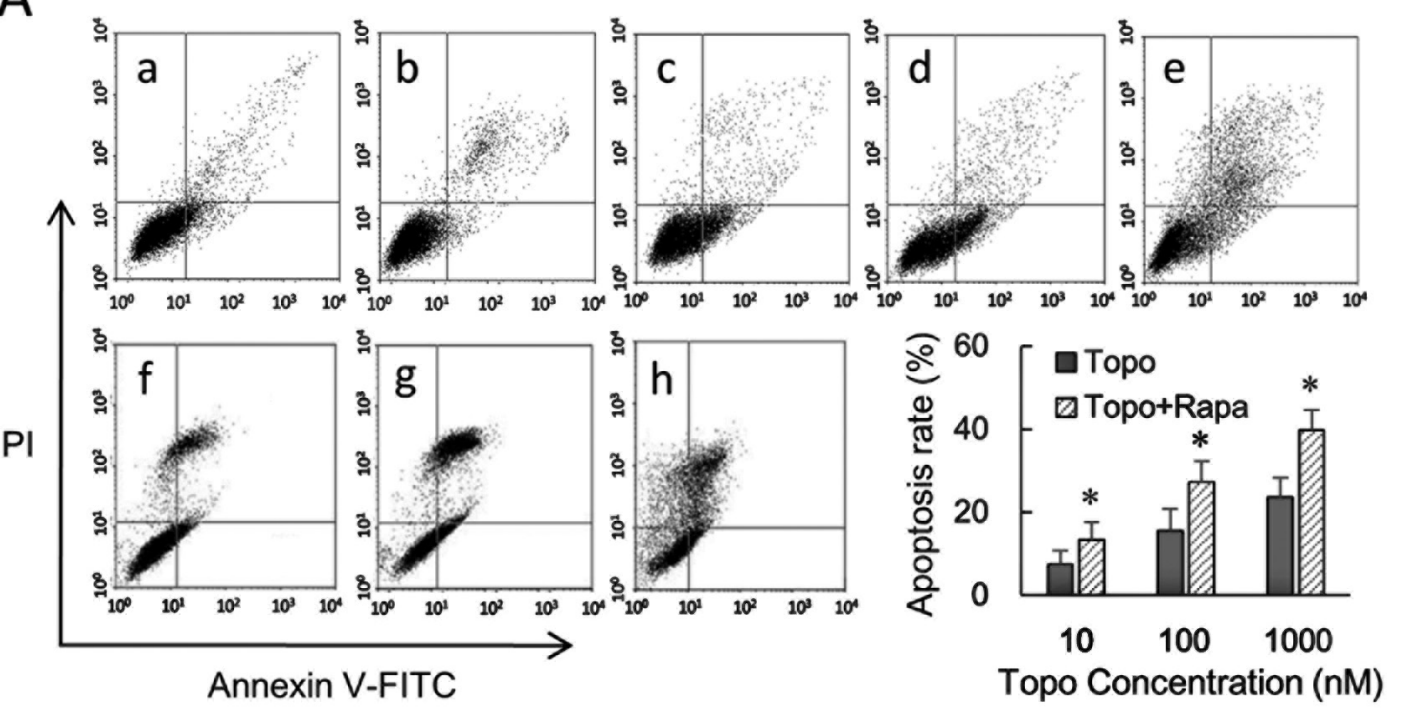

B
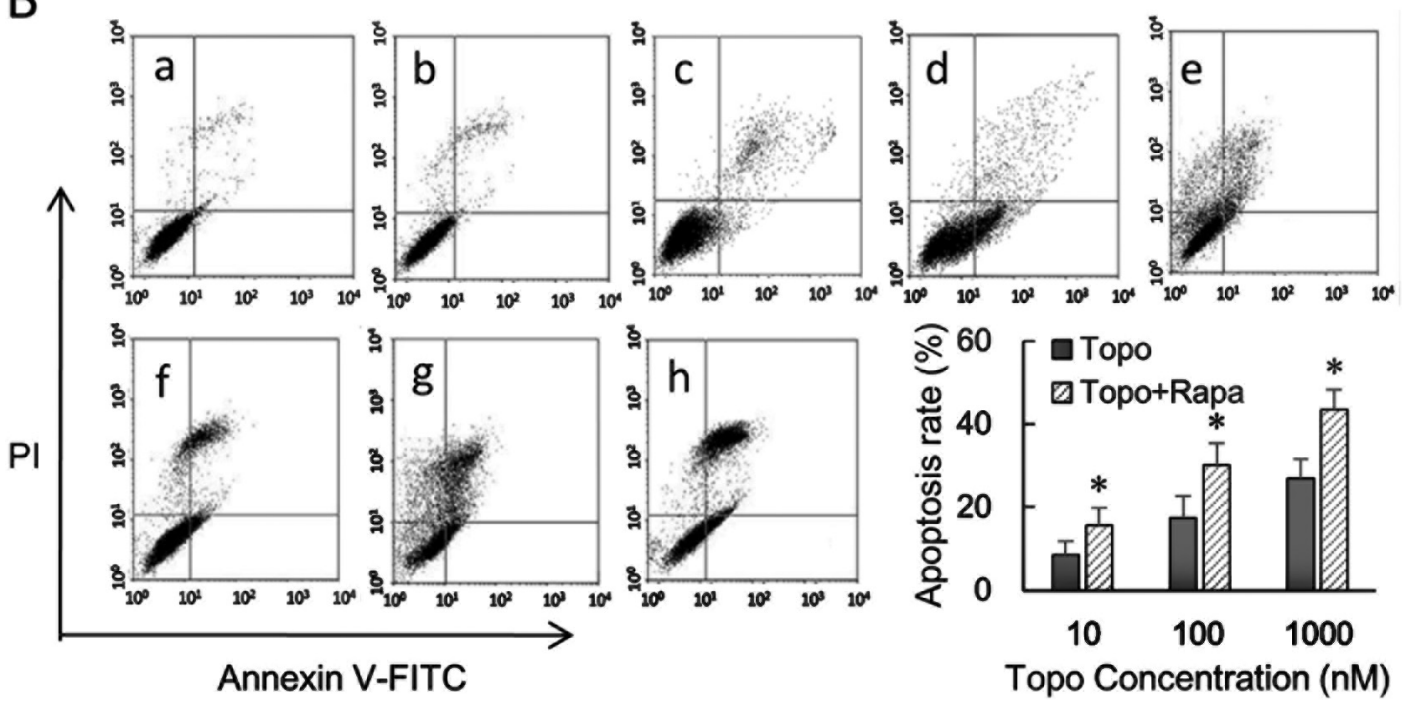

Figure 3. Effect of rapamycin pretreatment on topotecan-induced cell apoptosis in A2780cis (A) and COC1/DDP (B) cells. Cells were exposed to the following treatments: a) vehicle for $72 \mathrm{~h}, \mathrm{~b}) 10 \mathrm{nM}$ rapamycin for $24 \mathrm{~h}, \mathrm{c}$ ) vehicle for $24 \mathrm{~h}$ followed by $10 \mathrm{nM}$ topotecan for $48 \mathrm{~h}$, d) vehicle for $24 \mathrm{~h}$ followed by $100 \mathrm{nM}$ topotecan for $48 \mathrm{~h}$, e) vehicle for $24 \mathrm{~h}$ followed by $1,000 \mathrm{nM}$ topotecan for $48 \mathrm{~h}, \mathrm{f}$ ) $10 \mathrm{nM}$ rapamycin for $24 \mathrm{~h}$ followed by $10 \mathrm{nM}$ topotecan for $48 \mathrm{~h}$, $\mathrm{g}$ ) $10 \mathrm{nM}$ rapamycin for $24 \mathrm{~h}$ followed by $100 \mathrm{nM}$ topotecan for $48 \mathrm{~h}, \mathrm{~h}$ ) $10 \mathrm{nM}$ rapamycin for $24 \mathrm{~h}$ followed by $1,000 \mathrm{nM}$ topotecan for $48 \mathrm{~h}$. Cells were stained with PI and Annexin V and then subjected to flow cytometry assay. ${ }^{\star} p<0.05$, combined treatment $v s$. topotecan alone treatment. Topo, topotecan; Rapa, rapamycin. 
apoptotic cells were determined to be $13.4,27.2$, and $39.7 \%$, respectively, in A2780cis cells, and 15.6, 30.2, and 43.4\%, respectively, in COC1/DDP cells (Figure 3). These results
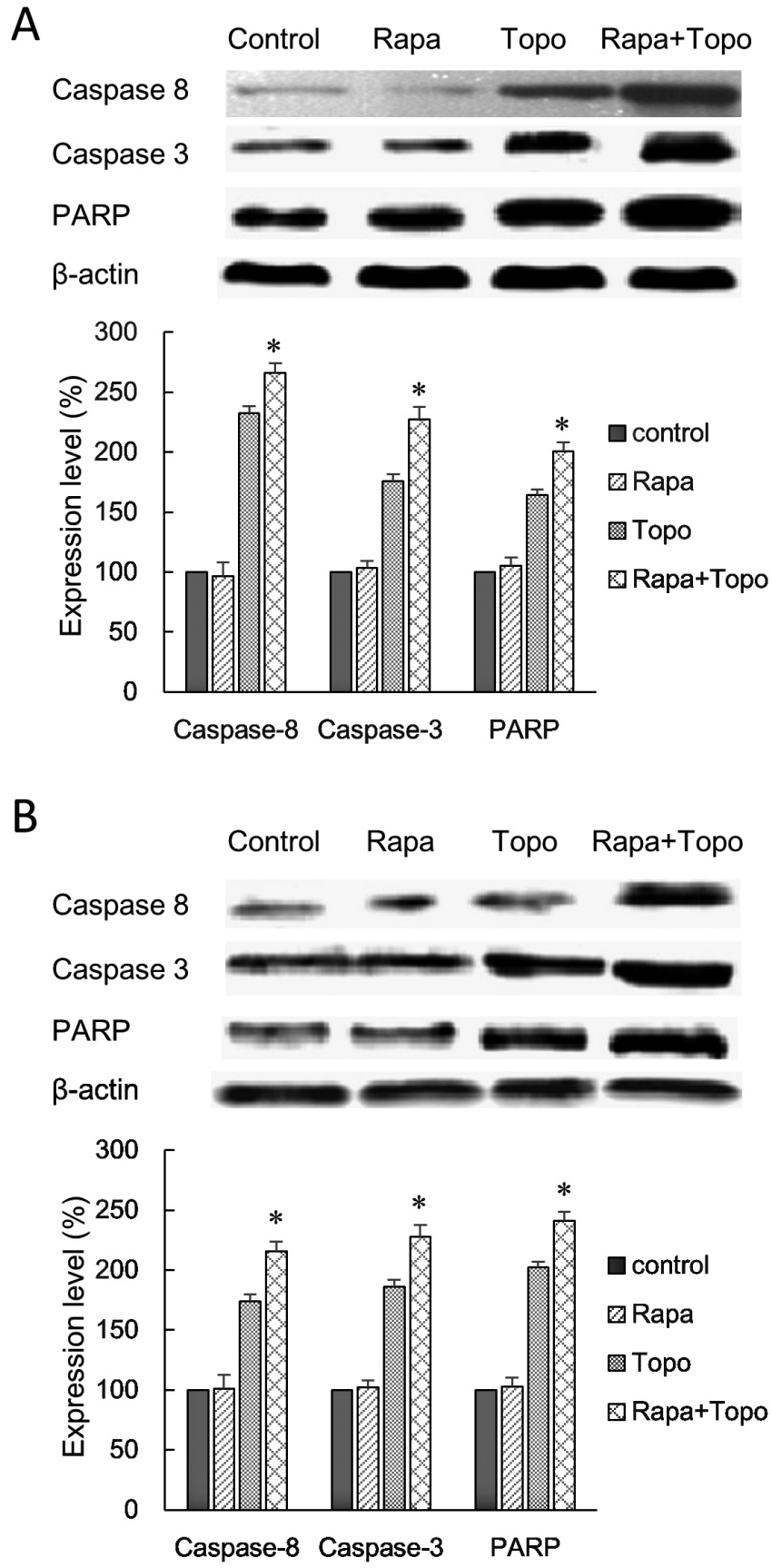

Figure 4. Expression levels of cleaved caspase-8, -3, and PARP in A2780cis (A) and COC1/DDP (B) cells. Cells were treated with $10 \mathrm{nM}$ rapamycin for $24 \mathrm{~h}$, vehicle for $24 \mathrm{~h}$ followed by $100 \mathrm{nM}$ topotecan for $48 \mathrm{~h}, 10 \mathrm{nM}$ rapamycin for $24 \mathrm{~h}$ followed by $100 \mathrm{nM}$ topotecan for $48 \mathrm{~h}$, respectively. Cells were lysed and total proteins were subjected to Western blotting. ${ }^{*} p<$ 0.05 , combined treatment $v s$. topotecan alone treatment. Topo, topotecan; Rapa, rapamycin. suggested that pretreatment of rapamycin increased the activity of topotecan in soliciting apoptosis in cisplatin-resistant ovarian cancer cells.

We further examined cell apoptosis by measuring the levels of apoptosis-related proteins including cleaved caspase-8, -3, and PARP in A2780cis and COC1/DDP cells. Western blotting showed that sequential treatment of rapamycin and topotecan had more potent effect than topotecan monotherapy in regulating the expressions of apoptotic proteins. Topotecan at $100 \mathrm{nM}$ for $48 \mathrm{~h}$ exposure, the levels of cleaved caspase- 8 , -3 , and PARP were increased by $132.6,95.6$, and $84.2 \%$, respectively, in A2780cis cells, and by 74.1, 95.9, and 102.3\%, respectively, in COC1/DDP cells (Figure 4). Rapamycin at $10 \mathrm{nM}$ for $24 \mathrm{~h}$ exposure did not obviously affect the levels of cleaved caspase-8, -3, and PARP in both A2780cis and COC1/DDP cells (Figure 4). When pretreatment with $10 \mathrm{nM}$ rapamycin for $24 \mathrm{~h}$, topotecan at $100 \mathrm{nM}$ for $48 \mathrm{~h}$ exposure increased the levels of cleaved caspase- $8,-3$, and PARP by $165.8,127.3$, and $100.5 \%$, respectively, in A2780cis cells; and by $115.6,127.6$, and $131.3 \%$, respectively, in COC1/DDP cells. Significant differences existed between combined therapy and topotecan monotherapy $(p<0.05)$ (Figure 4$)$.

p53 expression was decreased by rapamycin and increased by topotecan. p53 expression was determined in A2780cis and COC1/DDP cells subjected to rapamycin, topotecan, and their sequential combination treatment, respectively, using Western blotting. Results showed that rapamycin at $10 \mathrm{nM}$ for $24 \mathrm{~h}$ exposure decreased $\mathrm{p} 53$ expression by $67.3 \%$ in A2780cis cells ( $p<0.01$ vs. control) (Figure 5). On the other hand, topotecan at $100 \mathrm{nM}$ for $48 \mathrm{~h}$ exposure increased the levels of p53 by $32.5 \%$ ( $p<0.05 v$ s. control) in A2780cis cells (Figure 5). The expression of p53 in sequential treatment group was demonstrated to be lower than that in control and topotecan alone treatment group $(p>0.05$ vs. control; $p<0.05 v s$. topotecan alone). Similar with A2780cis cell line, p53 expression in COC1/DDP cells was significantly reduced by rapamycin and increased by topotecan (Figure 5). In addition, p53 level in sequential treatment group was less than that in control and topotecan alone treatment group ( $p$ $>0.05 v$ s. control; $p<0.05 v s$. topotecan alone). Since high expression of p53 could cause resistance of cancer cells to topotecan-induced apoptosis [18], downregulation of $\mathrm{p} 53$ by rapamycin might be the possible mechanism underlying the effect of rapamycin in augmenting topotecan-induced cell apoptosis in A2780cis and COC1/DDP.

Suppression of tumor growth in vivo. To assess the efficacy of the rapamycin-topotecan combination in vivo, an A2780cis human xenograft model was established and animals were randomly assigned to control group, rapamycin group, topotecan group, and drug combination group. Rapamycin dosed orally at $1.5 \mathrm{mg} / \mathrm{kg}$ slightly inhibited tumor growth by $5.6 \%$ compared to control (Figure 6A). Topotecan significantly reduced terminal tumor burden by $20.5 \%$ when dosed at $1.0 \mathrm{mg} / \mathrm{kg}$ (Figure 6A). The rapamycin-topotecan combination (1.5 and $1.0 \mathrm{mg} / \mathrm{kg}$, respectively) significantly reduced terminal tumor 
burden by $44.1 \%$ which is obviously higher than that of the corresponding monotherapy controls (Figure 6A). These data suggested that rapamycin and topotecan dosed in combination act synergistically in reducing overall tumor burden using the A2780cis ovarian cancer tumor model.

Oral rapamycin was generally well tolerated by mice with no significant loss of body weight ( $p>0.05 v s$. vehicle) (Figure $6 \mathrm{~B})$. Topotecan injection resulted in a significant reduction in body weight ( $p<0.05 v s$. vehicle). A significant loss of body weight was also observed in mice receiving the rapamycintopotecan combination (Figure 6B). However, there was no significant difference in body weight between combined treatment group and topotecan alone treatment group $(p>0.05)$.

\section{Discussion}

Topotecan is usually used to treat ovarian cancers that develop platinum-resistance. To enhance the efficacy of this drug, rapamycin, a mTOR specific inhibitor, was combined in the present study. We showed that pretreatment of rapamycin obviously enhanced the efficacy of topotecan in suppressing cell proliferation and soliciting cell apoptosis in two cisplatinresistant ovarian cancer cell lines A2780cis and COC1/DDP in vitro. The expressions of caspase- $8,-3$, and PARP were increased to higher levels in cells exposure to rapamycin-topotecan sequential treatment compared to topotecan treatment alone. Importantly, our results showed that combination of
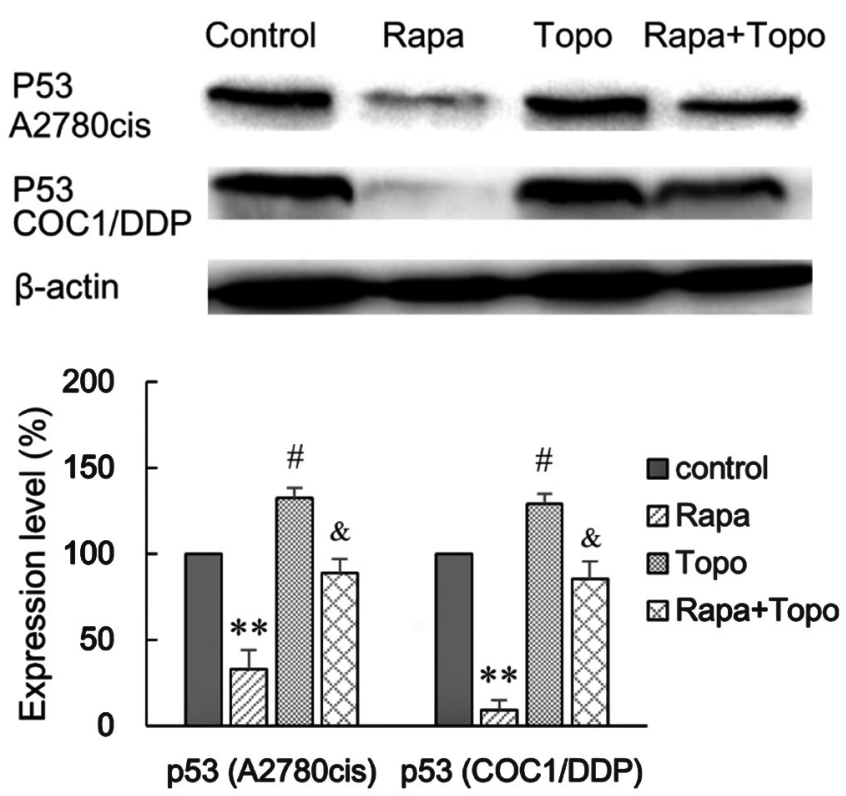

Figure 5. p53 expression in A2780cis and COC1/DDP cells. Cells were exposed to $10 \mathrm{nM}$ rapamycin for $24 \mathrm{~h}$, vehicle for $24 \mathrm{~h}$ followed by $100 \mathrm{nM}$ topotecan for $48 \mathrm{~h}, 10 \mathrm{nM}$ rapamycin for $24 \mathrm{~h}$ followed by $100 \mathrm{nM}$ topotecan for $48 \mathrm{~h}$, respectively. Cells were lysed and total proteins were subjected to Western blotting. ${ }^{\star *} p<0.01$, rapamycin treatment $v$ s. control. ${ }^{\#} p<$ 0.05 , topotecan treatment $v s$. control. ${ }^{\&} p<0.05$, combined treatment $v s$. topotecan alone treatment. Rapa, rapamycin; Topo, topotecan. rapamycin and topotecan significantly reduced tumor burden in ovarian cancer mouse xenograft model. These results suggested that rapamycin might be capable of sensitizing cisplatin-resistant ovarian cancer cells A2780cis and COC1/ DDP to topotecan chemotherapy.

mTOR belongs to the phosphatidylinositide- $3 \mathrm{OH}$ kinase (PI3K) related family of protein kinases and plays a central role in the regulation of cell growth and survival by integrating nutrient/energy signaling with that of growth factor signaling. Given tumor cells are more sensitive than normal cells to nu-

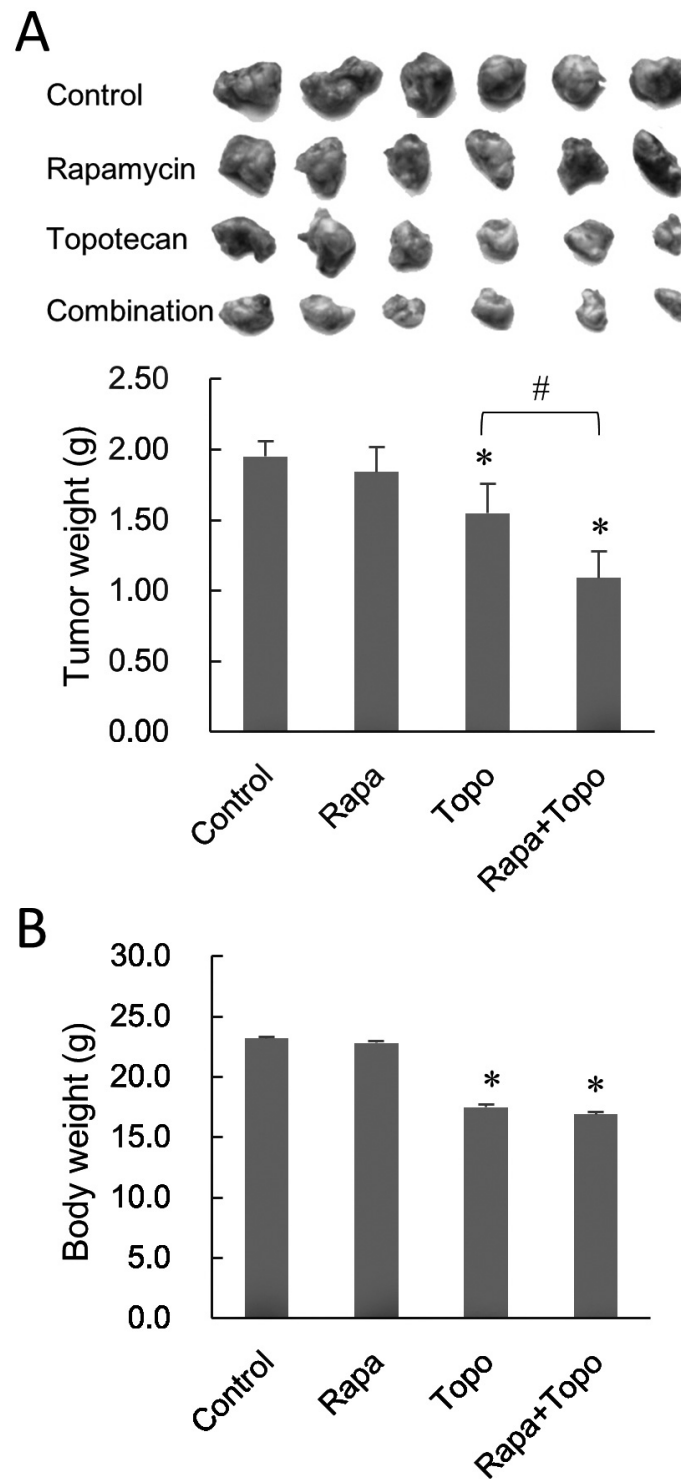

Figure 6. Effect of rapamycin, topotecan, and their combination on the growth of A2780cis xenografts (A) and body weight (B) of nude mice. Drugs were administered according to the description in "Materials and Methods". After experiment, tumor weight and body weight of mice in each group were obtained and compared. ${ }^{\star} p<0.05$ vs. control. ${ }^{*} p<0.05$, combined treatment $v s$. topotecan alone treatment. Topo, topotecan; Rapa, rapamycin. 
trients and energy supply, mTOR has been an important target for cancer treatment. Since the PI3K/AKT/mTOR is activated in approximately $70 \%$ of ovarian cancers [19], mTOR targeting agents including rapamycin and its closely related derivatives are currently undergoing phase I or II clinical studies either as single agent or in combination with chemotherapeutic agents in the treatment of ovarian cancers $[19,20]$. In the present study, we found that the levels of p-mTOR and its down-stream molecules including p-p70S6K and p-4E-BP1 were obviously higher in cisplatin-resistant cells A2780cis and COC1/DDP than that in the parental cisplatin-sensitive cells. It is possible that hyperactive mTOR survival cascade is involved in the sensitivity of ovarian cancer cells A2780cis and COC1/DDP to cisplatin or other chemotherapeutic drugs. These results provide a clue for testing the efficacy of an mTOR inhibitor rapamycin in combination of topotecan in treatment of platinum-resistant ovarian cancer in the current study.

We found p53 expression was significantly decreased in $\mathrm{A} 2780$ cis and COC1/DDP cells exposure to rapamycin for $24 \mathrm{~h}$, which might contribute to sensitizing the cells to topotecan-induced apoptosis. Topotecan is an inhibitor of Topo I, an enzyme that can cleave the DNA and covalently bound to the nicked DNA, forming the so-called Topo I-DNA cleavage complex [21]. Under physiological condition, Topo I-DNA complexes are reversible covalent intermediates catalyzing the cleavage-religation reaction of the enzyme. In the presence of topotecan, the cleavable complexes are stabilized and relegation of Topo I mediated DNA single-strand breaks are blocked, leading to accumulation of DNA strand breaks that may interfere with DNA replication [21]. Tomicic and co-workers showed that p53 mediated the repair of Topo Icleavable complex [18]. They showed that p53-deficient mouse embryonic fibroblasts (MEF) and p53 mutated glioblastoma cells U138 were significantly more sensitive to the apoptotic activity of topotecan than the p53-proficient and p53 wild-type counterparts. The authors suggested that tumor response to topotecan was dependent on the p53 level in cancer cells [18]. In the present study, we observed reduced p53 expression in A2780cis and COC1/DDP cells after rapamycin treatment, which may sensitize the cells to subsequent topotecan-induced apoptosis. Although exposure to topotecan increased p53 expression, the p53 level in combined treatment group was still lower than that in topotecan alone treatment group. Thus, down-regulation of p53 by rapamycin may be responsible for the enhanced antitumor effect of rapamycin-topotecan combined therapy.

Topotecan produces DNA damage that induces autophagy in cancer cells [22]. Previous studies revealed that p53 status affected cell response to topotecan via modulation of autophagy. Li et al. reported that DNA damage induced by topotecan treatment resulted in cytoprotective autophagy in colon cancer cells with wild-type p53 [23]. However, in cells with mutant p53 or p53 knockout, treatment with topotecan induced autophagy-associated cell death [23]. These results imply that p53-dependent induction of cytoprotective au- tophagy is a cell response that reduces cellular sensitivity to the DNA-damaging drug topotecan. We observed that rapamycin down-regulated p53 levels in A2780cis and COC1/DDP cells, which might alleviate the cytoprotective autophagy and thus enhance topotecan-induced apoptosis. The effects of rapamycin and topotecan on autophagy in cisplatin-resistant ovarian cancer cells warrants further studies.

In conclusion, suppression of mTOR by rapamycin reduced p53 expression and sensitized platinum-resistant ovarian cancer cells A2780cis and COC1/DDP to topotecan chemotherapy both in vitro and in vivo. This study provided evidence for possible usage of mTOR inhibitors such as rapamycin in combination of topotecan to treat platinum-resistant ovarian cancers. The efficacy and tolerance of this combined therapy in treating chemoresistant or recurrent ovarian cancers warrant further preclinical and clinical research in the future.

\section{References}

[1] WHO. GLOBOCAN 2012: Estimated Cancer Incidence, Mortality and Prevalence Worldwide in 2012. http: //globocan. iarc.fr/Pages/fact_sheets_cancer.aspx (accessed December 30, 2013).

[2] ARMSTRONG DK. Relapsed ovarian cancer: challenges and management strategies for a chronic disease. Oncologist 2002; 7 Suppl 5: 20-28. http://dx.doi.org/10.1634/theoncologist.7suppl 5-20

[3] PUJADE-LAURAINE E, HILPERT F, WEBER B, REUSS A, POVEDA A et al. Bevacizumab combined with chemotherapy for platinum-resistant recurrent ovarian cancer: The AURELIA open-label randomized phase III trial. J Clin Oncol 2014; 32: 1302-1308. http://dx.doi.org/10.1200/JCO.2013.51.4489

[4] MORRIS R, ALVAREZ RD, ANDREWS S, MALONE J, BRYANT C et al. Topotecan weekly bolus chemotherapy for relapsed platinum-sensitive ovarian and peritoneal cancers. Gynecol Oncol 2008; 109: 346-352. http://dx.doi. org/10.1016/j.ygyno.2008.02.028

[5] KANG H, KIM TJ, LEE YY, CHOI CH, LEE JW et al. Topotecan combined with carboplatin in recurrent epithelial ovarian cancer: results of a single-institutional phase II study. Gynecol Oncol 2009; 114: 210-214. http://dx.doi.org/10.1016/j. ygyno.2009.04.016

[6] REN Q, XIONG RX, WANG HZ, ZHOU X. Clinical efficacy of topotecan in the treatment of platinum-resistant palindromia ovarian cancer. China Oncol. 2011; 21: 207-210.

[7] GORDON AN, TONDA M, SUN S, RACKOFF W, DOXIL STUDY 30-49 INVESTIGATORS. Long-term survival advantage for women treated with pegylated liposomal doxorubicin compared with topotecan in a phase 3 randomized study of recurrent and refractory epithelial ovarian cancer. Gynecol Oncol 2004; 95: 1-8. http://dx.doi.org/10.1016/j. ygyno.2004.07.011

[8] LU X, WEI H, ZHANG X, ZHENG W, CHANG C et al. Rapamycin synergizes with low-dose oxaliplatin in the HCT116 colon cancer cell line by inducing enhanced apoptosis. Oncol Lett 2011; 2: 643-647. 
[9] KAWADA JI, ITO Y, IWATA S, SUZUKI M, KAWANO Y et al. mTOR Inhibitors induce cell-cycle arrest and inhibit tumor growth in Epstein-Barr virus-associated T and natural killer cell lymphoma cells. Clin Cancer Res 2014; 20: 5412-5422. http://dx.doi.org/10.1158/1078-0432.CCR-13-3172

[10] PENG DJ, WANG J, ZHOU JY, WU GS. Role of the Akt/ mTOR survival pathway in cisplatin resistance in ovarian cancer cells. Biochem Biophys Res Commun 2010; 394: 600-605. http://dx.doi.org/10.1016/j.bbrc.2010.03.029

[11] RAJE N, KUMAR S, HIDESHIMA T, ISHITSUKA K, CHAUHAN D et al. Combination of the mTOR inhibitor rapamycin and CC-5013 has synergistic activity in multiple myeloma. Blood 2004; 104: 4188-4193. http://dx.doi.org/10.1182/blood2004-06-2281

[12] MATSUZAKI T, YASHIRO M, KAIZAKI R, YASUDA K, DOI Y et al. Synergistic antiproliferative effect of mTOR inhibitors in combination with 5-fluorouracil in scirrhous gastric cancer. Cancer Sci 2009; 100: 2402-2410. http://dx.doi. org/10.1111/j.1349-7006.2009.01315.x

[13] PENCREACH E, GUERIN E, NICOLET C, LELONG-REBEL I, VOEGELI AC et al. Marked activity of irinotecan and rapamycin combination toward colon cancer cells in vivo and in vitro is mediated through cooperative modulation of the mammalian target of rapamycin/hypoxia-inducible factor-1alpha axis. Clin Cancer Res 2009; 15: 1297-1307. http://dx.doi. org/10.1158/1078-0432.CCR-08-0889

[14] ACEVEDO-GADEA C, SANTIN AD, HIGGINS SA, URVA $S$, RATNER E et al. Phase I clinical trial of the mammalian target of rapamycin inhibitor everolimus in combination with oral topotecan for recurrent and advanced endometrial cancer. Int J Gynecol Cancer 2014; 24: 528-533. http://dx.doi. org/10.1097/IGC.0000000000000085

[15] GAO RP, TANG W, GE XJ, JIANG LY, LUO J. Eeffect of mTOR pathway on carboplatin resistance in ovarian cancer cells. Chin Hosp Pharm J 2012; 32: 1536-1539.
[16] BEUVINK I, BOULAY A, FUMAGALLI S, ZILBERMANN F, RUETZ $S$ et al. The mTOR inhibitor RAD001 sensitizes tumor cells to DNA-damaged induced apoptosis through inhibition of p21 translation. Cell 2005; 120: 747-759. http:// dx.doi.org/10.1016/j.cell.2004.12.040

[17] ALVERO AB, BROWN D, MONTAGNA M, MATTHEWS M, MOR G. Phenoxodiol-topotecan co-administration exhibit significant anti-tumor activity without major adverse side effects. Cancer Biol Ther 2007; 6: 612-617. http://dx.doi. org/10.4161/cbt.6.4.3891

[18] TOMICIC MT, CHRISTMANN M, KAINA B. Topotecantriggered degradation of topoisomerase I is p53-dependent and impacts cell survival. Cancer Res 2005; 65: 8920-8926. http://dx.doi.org/10.1158/0008-5472.CAN-05-0266

[19] LI H, ZENG J, SHEN K. PI3K/AKT/mTOR signaling pathway as a therapeutic target for ovarian cancer. Arch Gynecol Obstet 2014; 290: 1067-1078. http://dx.doi.org/10.1007/s00404-014$\underline{3377-3}$

[20] ClinicalTrials.gov. http: //www.clinicaltrials.gov/ct2/result s?term $=$ Curcumin ++ alzheimer\&Search $=$ Search $($ accessed October 21, 2014).

[21] LUCAS CHAZIN ED, ROCHA REIS RD, VELLASCO JUNIOR WT, ELMOR MOOR LF, ALVES VASCONCELOS TR. An overview on the development of new potentially active camptothecin analogs against cancer. Mini Rev Med Chem 2014; 14: 953-962. http://dx.doi.org/10.2174/1389557514666141029233037

[22] WANG Y, PENG RQ, LI DD, DING Y, WU XQ et al. Chloroquine enhances the cytotoxicity of topotecan by inhibiting autophagy in lung cancer cells. Chin J Cancer 2011; 30: 690-700. http://dx.doi.org/10.5732/cjc.011.10056

[23] LI DD, SUN T, WU XQ, CHEN SP, DENG R et al. The inhibition of autophagy sensitises colon cancer cells with wild-type p53 but not mutant p53 to topotecan treatment. PLoS One 2012; 7: e45058. http://dx.doi.org/10.1371/journal. pone. 0045058 